\title{
Risk maps for evaluation of natural and man-made hazards
}

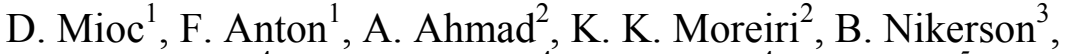 \\ E. McGillivray ${ }^{4}$, M. Mezouaghi ${ }^{4}$, L. Mofford ${ }^{4} \&$ P. Tang ${ }^{5}$ \\ ${ }^{1}$ National Space Institute, Technical University of Denmark, Denmark \\ ${ }^{2}$ Department of Geodesy and Geomatics Engineering, \\ University of New Brunswick, Canada \\ ${ }^{3}$ Faculty of Computer Science, University of New Brunswick, Canada \\ ${ }^{4}$ New Brunswick Emergency Measures Organization, Canada \\ ${ }^{5}$ New Brunswick Department of Environment, Canada
}

\begin{abstract}
With the advances of GIS technology it is possible now to map and determine the risks for different natural and man made risks and catastrophes. The large amounts of data can be processed, quantified and displayed on the digital maps allowing the decision makers to access the situation rapidly and take appropriate actions. The use of advanced hydrological tools for computation and modelling of natural hazards such as floods can be combined with the GIS that has the capability of decision support and advanced visualization to produce the models that will represent the risks of natural hazards and man-made disasters in the form of risk maps, where the risks are categorized and quantified. Furthermore, these processes can be automated what can allow for near real time access to the risk maps. This can greatly help decision makers with the emergency measures, and mitigation in most of the cases. In this article two case studies are presented. The first one deals with mapping of the flood risks while in the second one we present the geochemical mapping of contaminants that can pose risk to human health. The methodology used to derive the risk maps for these two cases are explained. The risks maps of flood hazards and maps of chemical contamination combined with the mining activities in the affected areas are also presented and explained.

Keywords: risk maps, flood, environmental pollution.
\end{abstract}




\section{Introduction}

The main goal of this research is to show the applicability of web based Geographic Information Systems (GIS) applications [1] for generation of risk maps. Risk maps are becoming more and more important in emergency management, natural disasters or man provoked disasters as well as in environmental protection [2]. We will show how the flood risk maps can be generated in near real time and we will further explore the potential for mapping of the catastrophic flood events. The two different cases will be presented; one dealing with natural floods and another one will present potential man made disaster, the catastrophic flooding caused by the dam burst. Furthermore, we will show how the risk maps can be developed and used to warn the population about the danger of environmental pollution related to the mining activities in the Canadian province of New Brunswick.

\section{Mapping the flood extent during the flood events}

It has been identified that more than $58 \%$ of the incorporated municipalities in the region of New Brunswick, reside within the Saint John River System [3]. The reason being that the waterways, during early settlement years, served not only as a source of major transportation for the early settlers, it also served as a source of livelihood for them as well. As the New Brunswick communities grew, so did occupation of flood plains to the point where substantial damages, human sufferings and indeed, loss if lives occurred during major floods.

Nation wide surveys have been made in the past and they clearly show that New Brunswick area is one of the highly vulnerable areas to floods.

There are many factors that may lead to floods, and people living in flood plains are most likely to be affected. A flood plain is whereby a flat or gently sloping land adjacent to a stream, during high stream flow conditions, caused by excessive rainfall or snowmelt or a combination of the two, become inundated by water [4]. A large number of people in the Fredericton area reside along the Saint John River and its tributaries. Web based GIS [5] is a methodology of building distributed GIS applications on the Internet [6]. Web GIS has the possibility of query on the website that can help to identify the properties and the people who might be affected by the floods, who may then been contacted to have ample evacuation time.

In this research near-real time prognostic of the flood maps were used [1]. Design floods have also been utilised, for the system to have the capability of producing property data of properties that may be affected by a particular design flood. This can be very helpful to flood practitioners to have an idea of the properties likely to be affected by such a flood (see Figures 1 and 2). Furthermore, city planners may also utilize the data when planning for future developments on flood prone areas to have an idea on the extent flood coverage of a possible maximal flood (shown in Figure 1). 


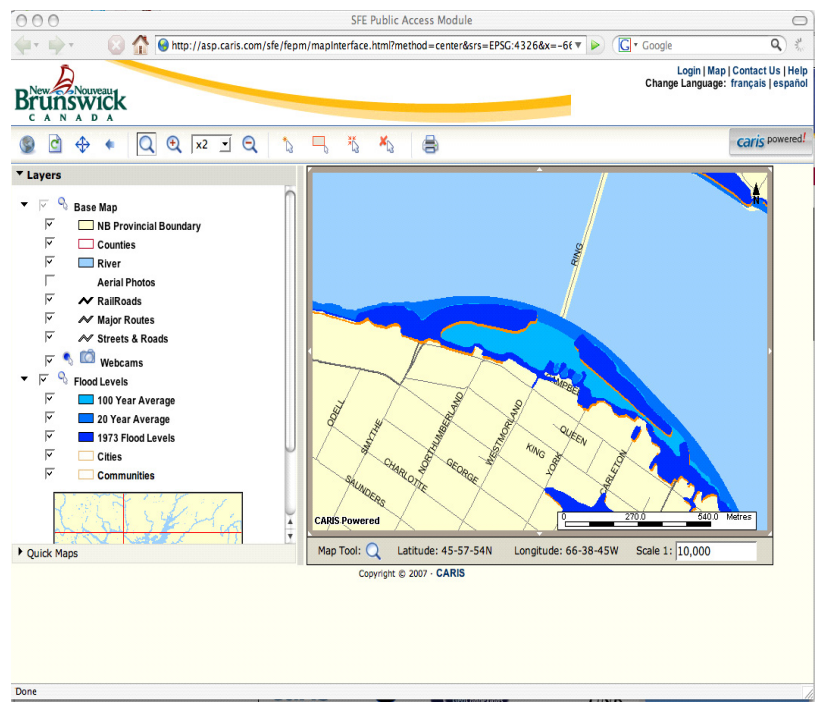

Figure 1: $\quad$ Map displaying statistically significant floods.

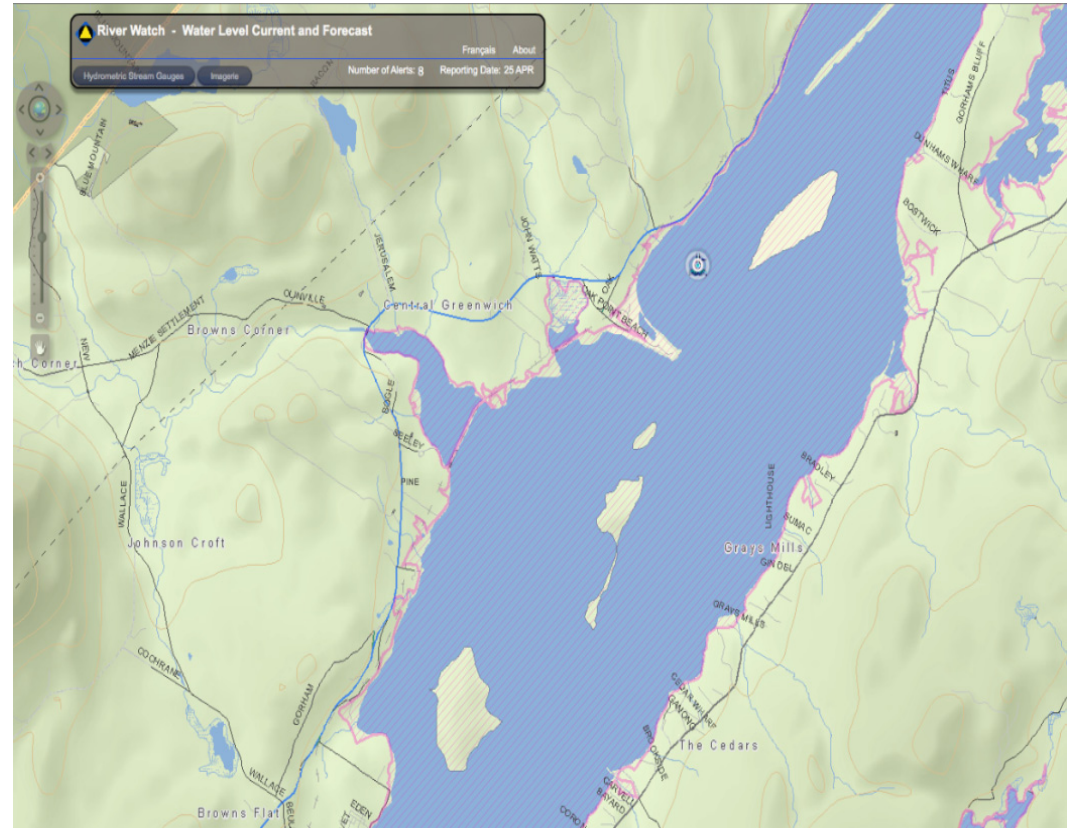

Figure 2: $\quad$ Flood warning application - river watch.

The idea is to use design floods, defined by Jeanne Andrews' publication on floods [7] to be extreme flood events selected and used for the design of structural measures such as dykes, spillways and floodways, as well as used in the delineation on topographic maps of flood hazard areas adjacent to rivers, lakes and the sea. The design floods used are of 1 in 20 year flood, that is a flood 
having a return period of 20 years on average or having a $0.05 \%$ chance of occurring in a given year. Other design floods are 1 in 100 year and 1 in 200 year flood. These are intersected with land use classification layer that include industrial areas, offices, parks, shopping areas and residential blocks of people residing within the flood plain (see Figure 1).

Furthermore, data showing the streams and rivers around the Fredericton area, as well as data showing road networks are used to calculate available evacuation routes [8].

The dynamic mapping of flood risk on daily basis was implemented by River Watch [1] by using the daily available data about the river water levels obtained from the water gauges. The new risk maps showing the extent of the floodplain are calculated using the hydrological modelling [1] interfaced with GIS [9] and displayed in dynamic and interactive fashion (see Figure 2).

As a part of flood modelling the possible catastrophic flood due to the Mactaquac dam burst have been mapped as well.

\section{Mapping the potential extent of the catastrophic flood event caused by the dam break}

The Mactaquac Dam is an embankment dam used to generate hydroelectricity and it is located near Fredericton, in the Canadian province of New Brunswick. It has a capacity to generate 653 megawatts of electricity from 6 turbines what represents approximately 20 percent of New Brunswick's power demand [10]. The Mactaquac dam burst is a hypothetical event that could have devastating consequences for the population of New Brunswick. Mactaquac dam was previously called the Mactaquac Generating Station.

The Mactaquac dam and powerhouse are located approximately $15 \mathrm{~km}(9.3$ mi) upstream from the city of Fredericton. The dam is an embankment dam consisting of a rock-fill structure sealed by clay. Mactaquac dam combines with two concrete spill-ways to form an arch across a narrow section of the river between the communities of Kingsclear on the west bank, and Keswick Ridge on the east bank [10].

The Mactaquac dam reservoir is raising 40 metres in height above the river level. Mactaquac reservoir (referred to locally as the "head pond") covers 87 square kilometres and extends 96 kilometres upstream, near Woodstock. The Mactaquac dam and powerhouse are a "run of the river" design, meaning that the reservoir has no additional holding capacity in the event of unusually high water flows, such as during the spring freshet [10].

The concrete portions of the Mactaquac dam (namely the spill-ways) are currently experiencing a problem of expanding concrete. In the time when it was built, locally quarried greywacke was used as the aggregate and is believed to be responsible for the alkali-aggregate reaction expansion. The Mactaquac dam is being monitored and extra maintenance work is being performed, although the spillway is expected to have a reduced life expectancy.

Previous work [1] on the flood mapping and prototype development relied on the commercial web GIS packages. In this research work the querying and data 
processing were slow and the application did not have the capability and functionality for displaying 3D buildings available from City of Fredericton [11]. We decided to try to use Google Earth instead for visualization of the catastrophic flooding scenario. The easy to use interface (see Figure 3) provided by Google Earth should also allow non-GIS experts to be in a position to interactively view and explore, as well as query the data base, to select different data variables and to view maps at several levels of detail. The hydrological modelling of the dam break was done as a part of the flood monitoring and prediction project by River Watch $[12,13]$. The earliest projections put the dam's end-of-life at 2028, instead of the original 100-year lifespan of 2068. Even worse, the officials will not say how much it will cost and when it will show up on the electrical utilities accounts [10].

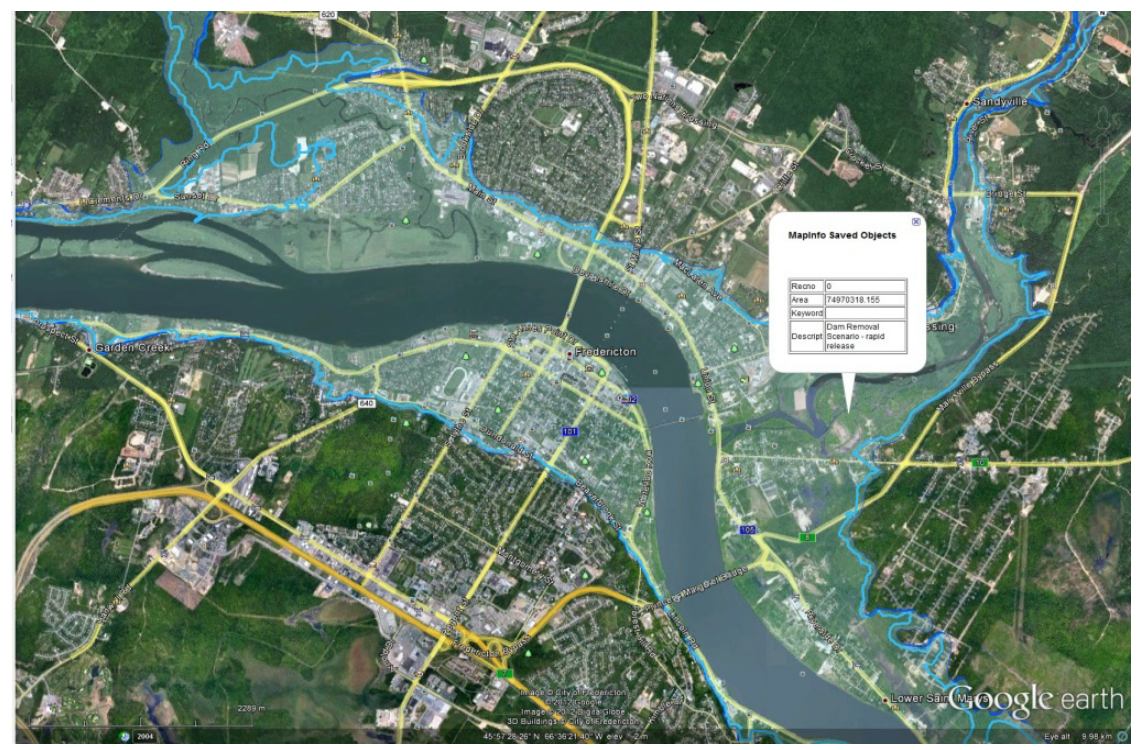

Figure 3: Two dam break scenarios integrated and displayed within Google Earth.

The two scenarios of Mactaquac dam breach were considered; one with the reservoir not full, and under the normal operation of the dam called "Sunny Day", while the other deals with the dam removal scenario [13] and it is shown in Figure 3. In Figure 4 the "Zoom-In" function allows us to identify the area of downtown Fredericton that could be affected by the catastrophic flood under the Mactaquac dam burst scenario. The models of 3D buildings developed by the City of Fredericton can be observed as well [11].

The Mactaquac dam burst scenario has also been implemented using ArcIMS, thus allowing for the query and spatial analysis [1]. The users of this application can visualize the extent of the flood in the city as well as the houses likely to be affected by such a scenario (see Figure 5). In Figure 6, we can visualize the 


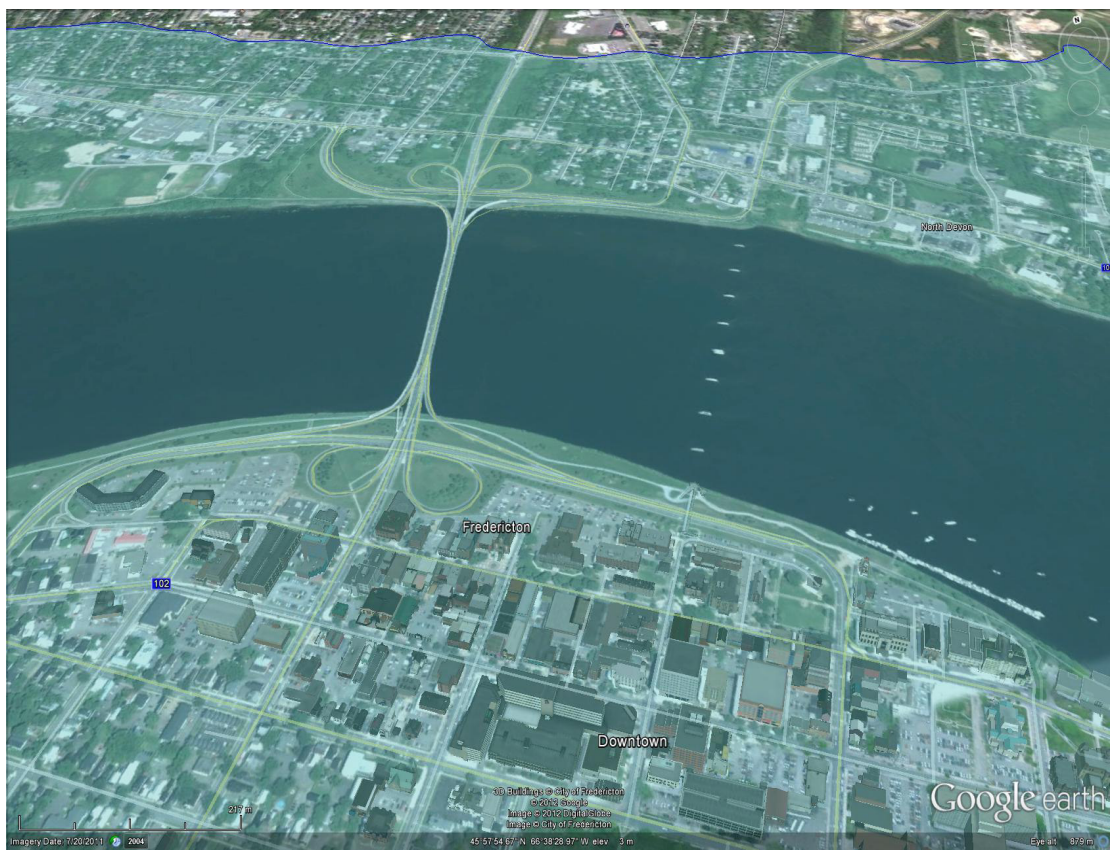

Figure 4: The view of the 3D buildings affected by catastrophic flood in downtown Fredericton.

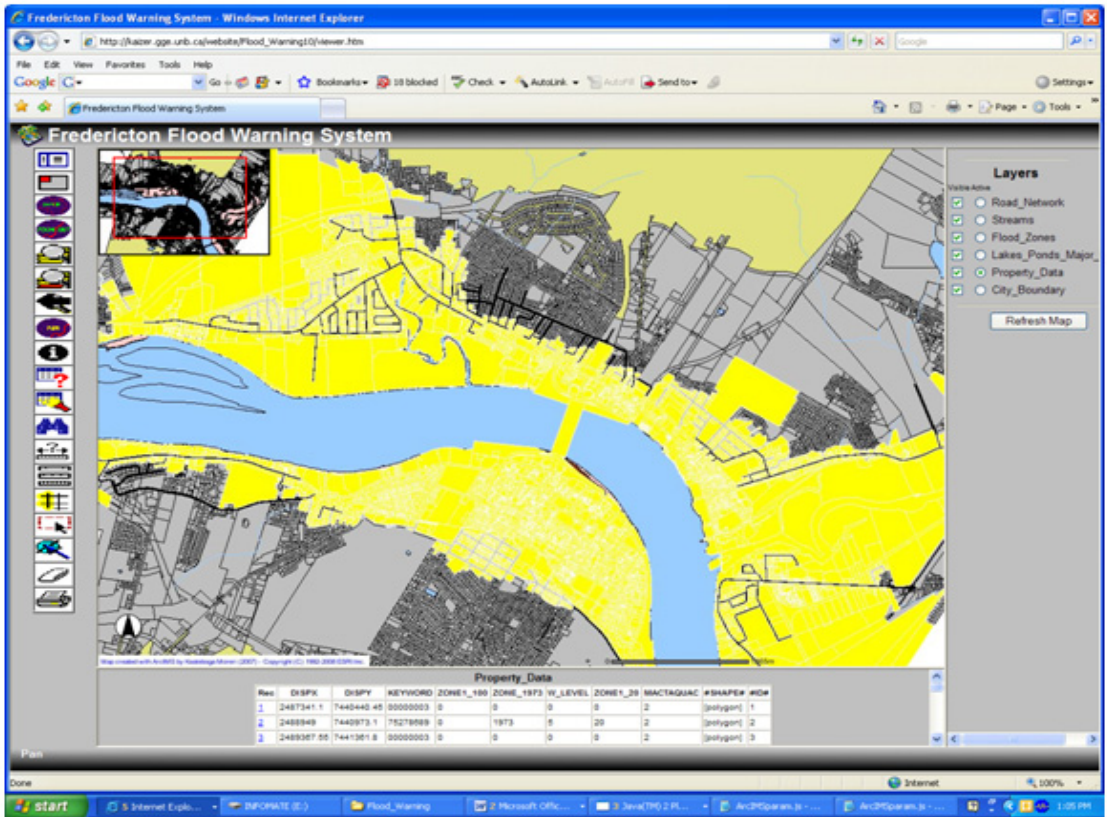

Figure 5: $\quad$ Web GIS application for Macquatac dam burst scenario. 
effect of the catastrophic flooding on downtown Fredericton as well as 3D buildings developed by the City of Fredericton. Furthermore, the shelters and the hospitals available to the population are identified and mapped [1].

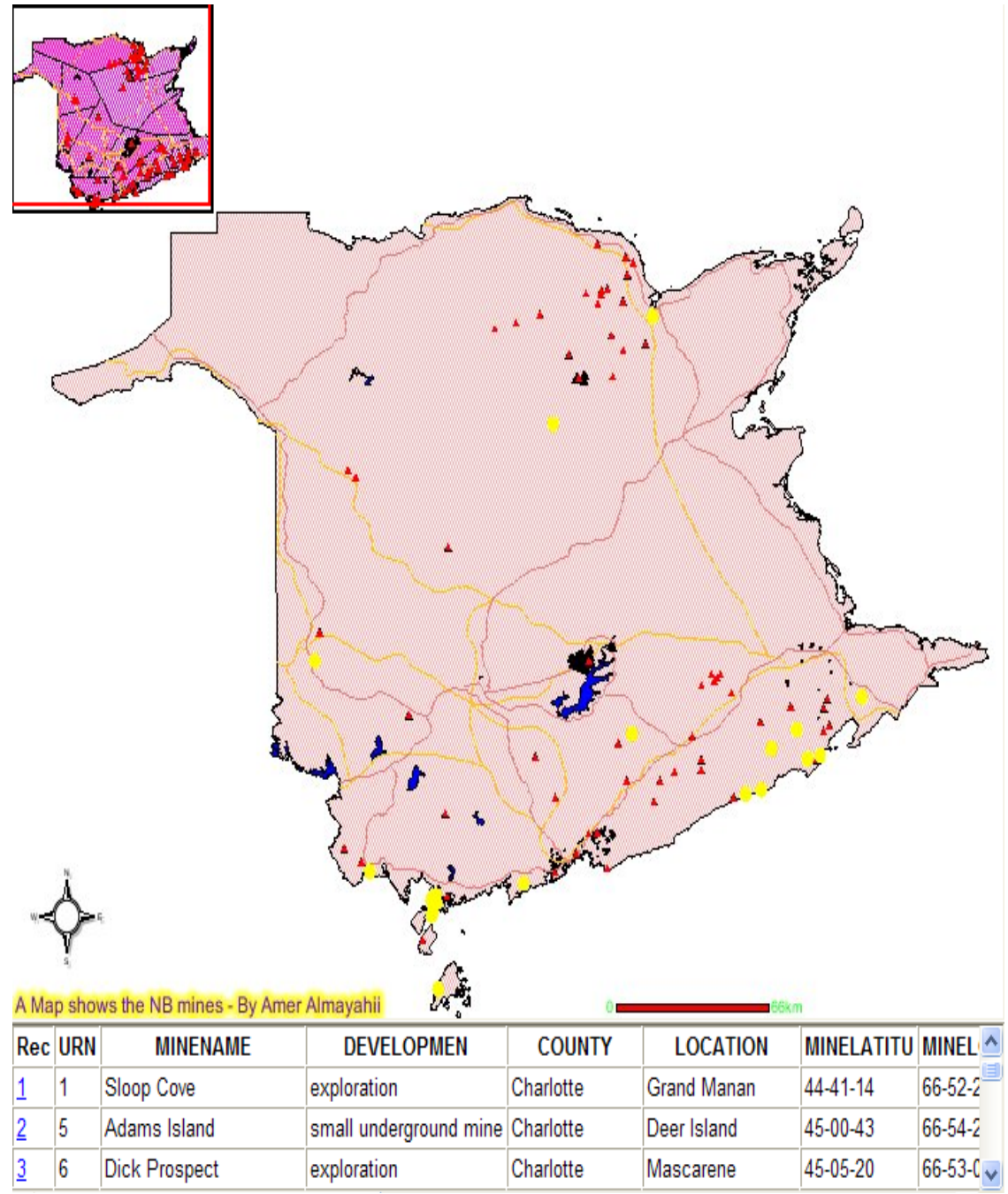

Figure 6: The Web-GIS application for interactive query and display of mining activities in New Brunswick.

\section{Mapping the potential pollution from the mining activities in New Brunswick}

Our second research goal was to map the contaminants (their spatial location) affecting the general population and the First Nations in New Brunswick within 
a Web based Geographic Information System. The Internet accessible mapping and spatial analysis of the contamination affecting the wild game and edible plants will allow First Nations and general population in New Brunswick (for the first time) to access the information about contaminated sites and avoid their traditional activities in contaminated areas.

The contamination has been detected in the areas of New Brunswick mines and abandoned tailing ponds located nearby (see Figure 6).

Exposure to lead and other heavy metals is known to affect the IQ and behaviour of children and cause blood, kidney and nervous disorders, along with a number of cancers [14]. It also causes serious developmental problems in children.

Data about potential contamination sites were obtained from the Geological Survey of New Brunswick. Data processing started with representing the contamination in all of the area of the province of New Brunswick, and then we made a comparison between the areas where the mines located and the rest of the province (see Figures 6, 7 and 8).

The processed data sets were uploaded to the Web GIS application, which can be queried interactively. For example, if we want to select all the mines where the copper is being exploited, and we entered the query, all of the mines that have the copper "Cu" as a one of its elements being exploited, will be shown as yellow dots on the map.

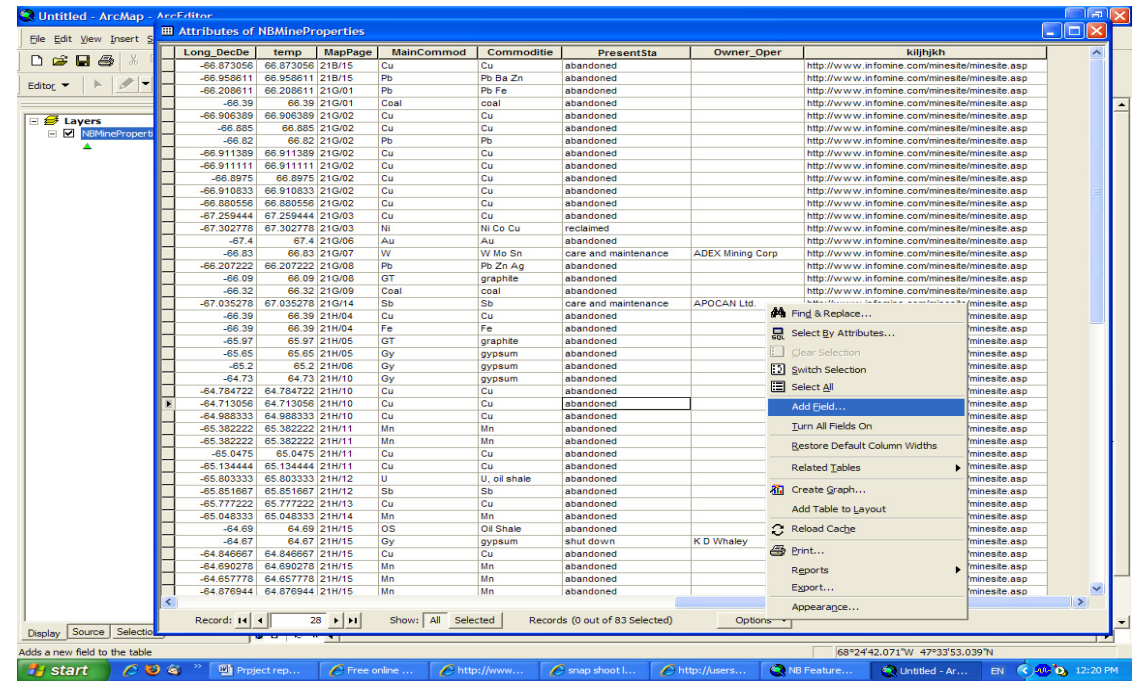

Figure 7: The data used in theWeb-GIS application for interactive query and display of mining activities in New Brunswick.

This map, showing the mines and the concentration of heavy metals (see Figure 8), allows a better understanding and visualization of the mines activities and potentially of the contamination in the area surrounding the mines or even occurring naturally in the specific geological rock formations. 


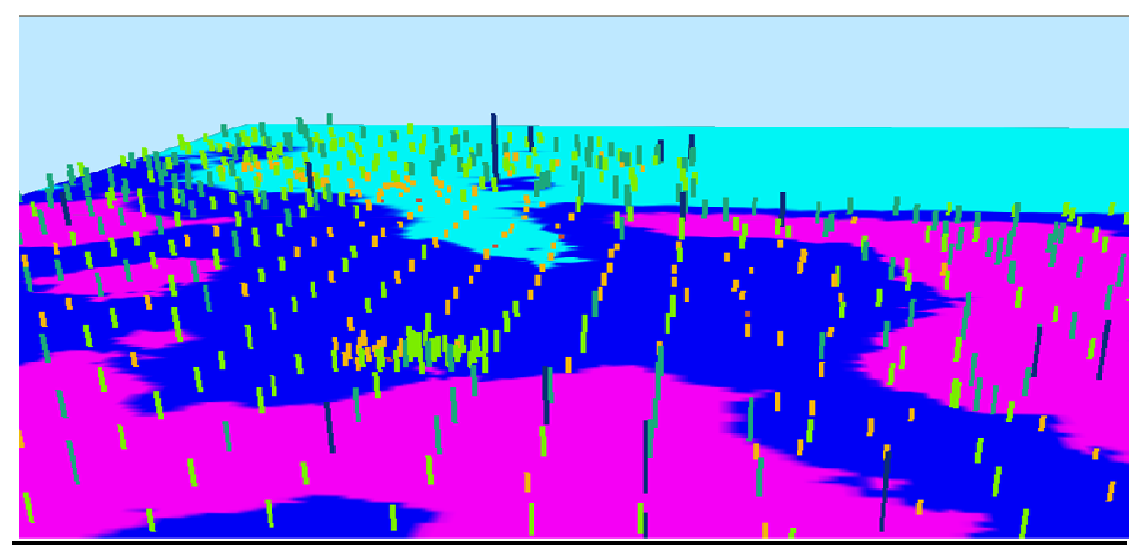

Figure 8: $3 \mathrm{D}$ model showing the concentrations of as and $\mathrm{Cr}$ produced with Krigging interpolation method.

It provides a new visualization tool and access to the existing data about the contamination from mining activities that might help people to better understand the problem from different perspective. It shows the effectiveness of each mine, its characteristics and classifies them according to their locations, importance and status.

Users of this Web GIS site are able to extract information, on demand, in realtime, of any mine exploitation to determine if the contamination is increasing. This provides the basis for an easy assessment of the current situation by collecting additional samples for the same area to check the contamination concentration.

In this way people will be more aware of the soil contamination concentration (in a form of a map) of the areas that they live in.

Additional geochemical studies are needed in order to investigate the geological formations and its toxicity of certain sites. The existing knowledge about the tailing ponds that are affecting nearby soil and water resources can be integrated in the maps. Furthermore, the maps showing the mining activities and contaminated areas are helping the people to understand the situation and be more aware of the problem, especially that it can affect their wildlife, plants, animals, fishery, recreation, sensitive areas and cultural resources.

In addition, the government's support in finding a reasonable solution to reduce the risks of contamination in the mining areas is needed.

\section{Result and conclusions}

In this research we have shown that with the recent advances of GIS technology, it is now possible to map and determine the risks (together with their magnitude) of different natural hazards and man-made catastrophes. Very large amounts of collected spatial and non-spatial data can be processed, quantified and displayed 
on digital maps, even in near real time applications thus allowing decision makers to assess the situation rapidly and take appropriate actions [14].

The use of advanced tools for computation and modelling of natural hazards such as floods can be combined with a GIS that has the capability of decision support and advanced visualization to produce the models, that represents the risks of natural hazards and man-made disasters in the form of dynamic risk maps, where the risks are categorized and quantified. In this paper we have shown that the simple mapping application can be done using Google Earth, and provides excellent visualization of the effects of the catastrophic flood caused by the Mactaquac dam breach. In addition, the use of Web GIS commercial software allowed for query and spatial analysis. Furthermore, the mapping of the contamination from mining activities has been shown.

In this research project we have shown that all these data processing and mapping can be automated, enabling near real time access to the risk maps via map servers. This can greatly help general public as well as to decision makers with the emergency measures and mitigation in most of the cases. Furthermore, their significance for decision-making and risk prevention and mitigation can be evaluated for future real situations.

\section{Acknowledgements}

This project was financially supported, in part, by the N.B. Emergency Measures Organization and by the Canadian Department of Natural Resources Geoconnections program as well as by University of New Brunswick and New Brunswick Innovation Foundation (NBIF). The IT Division of the City of Fredericton and Geological Survey of New Brunswick provided datasets available for this project. The New Brunswick Department of Environment has provided data and expertise related to hydrological modelling, and the NB Emergency Measures Organization helped with their expertise and additional funding for this project.

\section{References}

[1] Mioc, D., Moreiri, K.K., Nkhwanana, J.N., Anton, F., Nikerson, B., McGillivray, E., Morton, A. and Tang, P., On-line early warning system for evacuation of socially vulnerable population during flooding. Flood Recovery, Innovation and Response III, ed. D. Proverbs, S. Mambretti, C.A. Brebbia, D. de Wrachien, WIT Transactions on Ecology and the Environment vol. 159 (ISBN: 978-1-84564-588-5), pp. 67-78, 2012.

[2] Konecny, M., Early Warning and Crisis Management Cartographic and Geographic Information Research Agenda. Proc. of the $4^{\text {th }}$ International Conference on Cartography and GIS, Vol. 2., June 18-22, Albena, Bulgaria, pp. 7-16, 2012.

[3] New Brunswick Department of Environment, Water Resources Branch, Fredericton Planning Region, Water Resources Review, Report I - 8001, 8 pp. 1980. 
[4] Spear, MacDonald and Associates and Cumming - Cockburn and Associates, Hydrotechnical study of the Walker Brook flood plain, Restigouche County, Summary and main reports to Canada-New Brunswick Flood Damage Reduction Program for a hydrotechnical study of the Walker Brook flood plain, Moncton, N.B. : Spear, MacDonald, 1 v. (various pagings) : ill., maps ; $28 \mathrm{~cm}$. 1983, revised in 1985.

[5] Zipf, A. and Leiner, R., Mobile Internet GIS based Flood Warning and Information Systems, 2nd Symposium on Location Based Services and TeleCartography, Vienna, Austria, 2004.

[6] Shea, G. Y. K. A Web-Based Approach to the Integration of Diverse Data Structures for GIS, School of Surveying and Spatial Information Systems, Sydney, N.S.W., 43 pp. 2001.

[7] Andrews, J. (Ed.), Flooding, Canada Water Book. Cat. No. En3796/1993E. Ottawa: Ecosystem Sciences and Evaluation Directorate, Economics and Conservation Branch, Environment Canada. Published by: Canada Communication Group, 1993.

[8] Mioc, D., Nickerson, B., Anton, F., Fraser, D., McGillivray, E., Morton, A., Tang, P., Arp, J.P. and Liang, G., Web-GIS application for flood prediction and monitoring, International Conference on Flood Recovery Innovation and Response, London, WIT Transactions on Ecology and the Environment (ISBN: 978-1-84564-132-0), WIT Press, pp. 145-154, 2008.

[9] Mioc, D., Anton, F., Nickerson, B., Santos, M., Adda, P., Tienaah, T., Ahmad, A., Mezouaghi, M., MacGillivray, E., Morton A. and Tang, P., Flood Progression Modelling and Impact Analysis, Efficient Decision Support Systems - Practice and Challenges in Multidisciplinary Domains, Chiang Jao (Ed.), ISBN: 978-953-307-441-2, InTech, pp. 227-246, 2011.

[10] Wikimedia Foundation Inc., Mactaquac dam. Wikimedia Foundation, the Free Encyclopedia, http://en.wikipedia.org/wiki/Mactaquac,_New_ Brunswick, accessed 2012.

[11] Lunn, R., Google 3D buildings Fredericton, http://www.youtube.com /watch?v=2WqqYFU7y2g, accessed 2012.

[12] River watch, http://geonb.snb.ca/riverwatch, accessed 2012.

[13] Tang, P., Price, R. and Howe, M., The Saint John River Forecast System an Integrated Approach, 56 ${ }^{\text {th }}$ Annual Eastern Snow Conference, Fredericton, N.B., Canada, June 2-4, 1999, http://www.easternsnow.org /meetings/1999/final_program.html

[14] Chowdhury B. A. and Chandra, R. K., Biological and health implications of toxic heavy metal and essential trace element interactions. Prog Food Nutr Sci.11(1), pp. 55-113, 1987.

[15] Mioc, D., Anton, F., Moreiri, K.K., Nickerson B., MacGillivray, E., Mezouaghi, M., Mofford L. and Tang, P., Visualization of the impact of the catastrophic flood events. Proc. of the $4^{\text {th }}$ International Conference on Cartography and GIS, Vol. 2., June 18-22, Albena, Bulgaria, pp. 63-71, 2012. 